\title{
Effect of UAV prewetting application during the flowering period of cotton on pesticide droplet deposition
}

\author{
Weixiang YAO ${ }^{1,2}$, Xianju WANG ${ }^{2,3}$, Yubin LAN $(\bowtie)^{1,2}, J^{1} J I N^{1,2}$ \\ 1 College of Engineering, South China Agricultural University, Guangzhou 510642, China \\ 2 National Center for International Collaboration Research on Precision Agricultural Aviation Pesticides Spraying Technology, \\ Guangzhou 510642, China \\ 3 College of Electronic Engineering, South China Agricultural University, Guangzhou 510642, China
}

\begin{abstract}
Prewetting process can reduce the contact angle between the droplet and the leaf blade, so that the droplet can more easily wet and spread, thereby increasing the quantity of deposition. To improve the effectiveness of pesticides on cotton leaves, prewetting by single-rotor electric unmanned aerial vehicles (UAV) was studied, focusing on the effects of pesticide deposition on cotton leaves during the flowering period. Cotton leaves in $0^{\circ}-$ $30^{\circ}, 30^{\circ}-60^{\circ}, 60^{\circ}-90^{\circ}$ leaf blade angle ranges (angle between the leaf blade and the horizontal plane) were examined. In the first experiment, four different prewetting volumes $(0,1.6,3.2$ and $4.8 \mathrm{~L})$ were sprayed by a singlerotor electric UAV on four cotton plots (plots A-D) each with an area of $120 \mathrm{~m}^{2}$, and then each area was sprayed with a $0.8 \%(\mathrm{w} / \mathrm{v})$ ponceau $2 \mathrm{R}$ solution by another singlerotor electric UAV. The results revealed that with no prewetting, droplet deposition quantity decreased with increasing leaf blade inclination. After prewetting, the mean droplet deposition quantity on plots B, C and D increased by $39.8 \%, 9.7 \%$ and $24.9 \%$, respectively. The prewetting rate of $1.6 \mathrm{~L}$ per $120 \mathrm{~m}^{2}$ had the most significant effect on improving the deposition of droplets. It was also found that the mean droplet deposition quantity in each leaf blade angle range increased after prewetting. For the leaf blade angle range $60^{\circ}-90^{\circ}$, this increase was the most pronounced, with $0.043,0.062,0.057$ and $0.048 \mu \mathrm{L} \cdot \mathrm{cm}^{-2}$ in plots $\mathrm{A}-\mathrm{D}$, respectively. Also, droplet deposition uniformity in the leaf blade angle range $60^{\circ}-90^{\circ}$ was better after prewetting. These results should provide a valuable reference for future research and practice to improve the effectiveness of pesticides applied to cotton by aerial applications.
\end{abstract}

Keywords aerial spray, cotton, deposition, flowering period, leaf angle, prewetting, UAV

Received November 30, 2017; accepted March 25, 2018

Correspondence: ylan@scau.edu.cn

\section{Introduction}

The flowering period of cotton is from flowering to boll opening, which is the most sensitive period for water supply, with a high incidence of pests and diseases ${ }^{[1,2]}$. Therefore, it is important to ensure full water supply and pest control during the flowering of cotton ${ }^{[3,4]}$. In recent years, unmanned aerial vehicles (UAV) have been introduced as carriers to apply chemicals for the prevention and control of pests and diseases of cotton ${ }^{[5-7]}$, due to their high efficiency, strong capability, low damage to crops and low cost. The spraying of pesticides by UAV usually involves low volumes and high concentrations with small droplet size because of the UAV weight and tank limits ${ }^{[8,9]}$. Consequently, the volume of spray per unit area is much lower than for spraying with ground-based machinery ${ }^{[10]}$. In addition, cotton usually has a high planting density with dense foliage during the flowering period ${ }^{[11]}$, so it is imperative to ensure effective droplet deposition of pesticides on cotton leaves.

The surface wetting characteristics of leaves and the inclination of leaf blades have been shown to have a significant effect on the deposition of pesticide droplets in a large number of studies ${ }^{[12-19]}$. Yang et al. ${ }^{[12]}$ carried out an indoor spraying test with different leaf inclination angles in cotton, rice and wheat using a spraying crane. The results showed that better deposition on the plant leaves was associated with good surface wettability (cotton), and low inclination angle. Xu et al. ${ }^{[13]}$ analyzed the effects of application volume, droplet size, blade inclination and spray adjuvant on the deposition of pesticides on rice leaves and found that of the four factors the blade inclination had the greatest influence on deposition. Lan et al. ${ }^{[14]}$ evaluated the wetting and deposition effects of four different aviation adjuvants on cotton leaves in fixed-wing aircraft spray tests, and showed that the use of adjuvants can help promote better wetting of liquids on cotton leaves, and thus increase the deposition 
quantity. Jia et al. ${ }^{[15]}$ studied the relationship between droplet spray angles of small diameter droplets and wetting characteristics of plant leaf surfaces, and found that by controlling the spray parameters the best spraying deposition can be achieved. In addition, the effect of the prewetting action of dew on pesticide deposition on rice leaves was studied and indicated that dew can significantly increase the droplet deposition quantity ${ }^{[16]}$. In other research, it has also been found that the contact angle of droplets falling on dry leaf blade surfaces was much smaller than for those falling on blades prewet with liquid, with this smaller contact angle improving wettability ${ }^{[17-19]}$.

Although there has been considerable research on surface wetting characteristics of plant leaves and the inclination of leaf blades, there has been no detailed analysis of pesticide deposition using UAV in cotton, especially for prewetting applications. This paper reports an experiment using a small, single-rotor, electric UAV spray with different prewetting capacity based on the precision operating flight parameters obtained by a light airborne BeiDou Real-time kinematic (RTK) differential system. The deposition quantities on cotton leaves at different inclination angles during the flowering period were analyzed, and corresponding conclusions should provide a theoretical guide for improving the application of pesticides by UAV in cotton.

\section{Materials and methods}

\subsection{Experimental site and UAV}

The experiment was conducted at the research farm $\left(85^{\circ}\right.$ $98^{\prime} \mathrm{E}, 44^{\circ} 56^{\prime} \mathrm{N}$ ) of Shihezi City, Xinjiang Region, China. The test crop was cotton in the flowering period with a planting density of $1.8 \times 10^{5}$ plants per $\mathrm{hm}^{2}$, planted with narrow and broad row widths $(15$ and $60 \mathrm{~cm})$ at a plant spacing of $9 \mathrm{~cm}$. Each plant had an average 25 leaves in 6

(a)

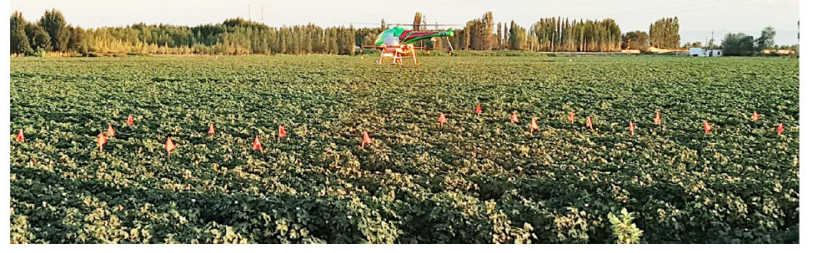

layers and average height of $60-80 \mathrm{~cm}$.

Two HB-Y-15L single-rotor electric UAVs (High Technology New Farming Co., Ltd, Shenzhen, China), designated $U A V_{X}$ and $U A V_{Y}$, were used in spraying experiments. The UAV and spraying test sites are shown in Fig. 1. $U_{A} V_{X}$ was used for water spray prewetting, and $\mathrm{UAV}_{\mathrm{Y}}$ for pesticide spraying operations. A light airborne BeiDou RTK differential system developed by South China Agricultural University with RTK differential positioning function was also used. The data acquisition interval was $0.1 \mathrm{~s}$ for recording flight parameters in real time and drawing actual operation trajectories as references for spray effect analysis. The specifications of the UAV and carrying equipment are listed in Table 1.

The UAV spray was equipped with pressure fan-shaped nozzles facing downwards with 5 nozzles at $3550 \mathrm{~mm}$ intervals along the direction of the spray bar perpendicular to the axis of the aircraft. Total flow rate was measured at $2.4 \mathrm{~L} \cdot \mathrm{min}^{-1}$.

\subsection{Experimental design}

A staining agent, $0.8 \%(\mathrm{w} / \mathrm{v})$ ponceau 2R (Huyu Biotechnology Co., Ltd, Shanghai, China) dissolved in deionized water was used as a substitute for pesticide in spraying operations. Sample collection cards, $76 \mathrm{~mm} \times$ $26 \mathrm{~mm}$, were water-sensitive paper (WSP) (Syngenta Crop Protection LLC, Basel, Switzerland).

Four areas within a cotton field $(20 \mathrm{~m} \times 6 \mathrm{~m})$ were selected as test plots (plots A-D) with the inter-block spacing $10 \mathrm{~m}$. The central axis of each plots was taken as the main route for spraying operations. According to the effective swath width of the UAV, each plot had a UAV acceleration area $(10 \mathrm{~m} \times 6 \mathrm{~m})$ and a sampling area $(10 \mathrm{~m}$ $\times 6 \mathrm{~m})$. The sampling area consisted of nine sampling points with horizontal spacing of $2 \mathrm{~m}$ and longitudinal spacing of $3 \mathrm{~m}$ (Fig. 2a), which confirmed that four singlepass application tracks were in accordance with the set trajectory (Fig. 2b).

(b)

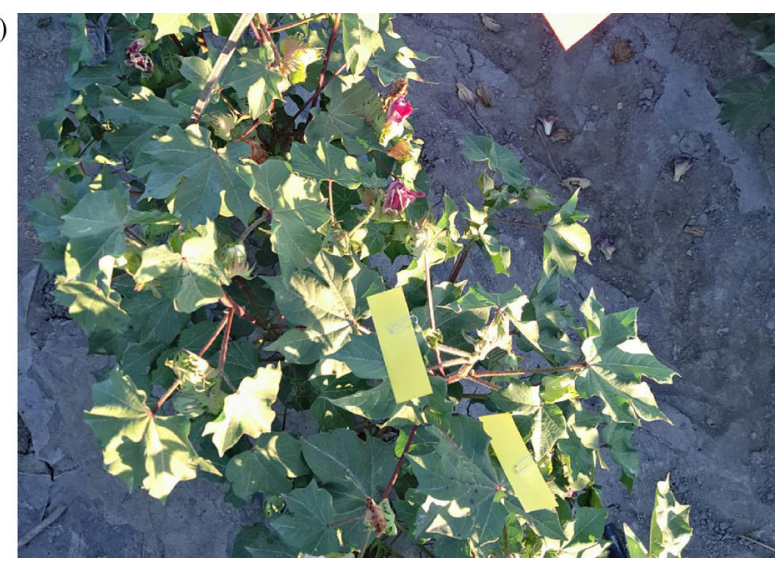

Fig. 1 UAV and test site. (a) Spray test site; (b) layout of sampling points. 
Table 1 Specifications of the unmanned aerial vehicle (UAV) and its carrying equipment

\begin{tabular}{lc}
\hline Main parameter & Norms and numerical \\
\hline UAV type & HB-Y-15L \\
Size/mm & $1955 \times 455 \times 625$ \\
Main/tail rotor diameter/mm & $2143 / 360$ \\
Maximum load $/ \mathrm{L}$ & 16 \\
Setting spray volume $/\left(\mathrm{L} \cdot \mathrm{hm}^{-2}\right)$ & 15 \\
Flight height/m & $1-3$ \\
Flight speed $/\left(\mathrm{m} \cdot \mathrm{s}^{-1}\right)$ & $0-8$ \\
Effective swath $/ \mathrm{m}$ & $4-7$ \\
BeiDou plane accuracy $/ \mathrm{mm}$ & $\left(10+5 \times \mathrm{D} \times 10^{-7}\right)^{\mathrm{a}}$ \\
BeiDou elevation accuracy $/ \mathrm{mm}$ & $\left(20+1 \times \mathrm{D} \times 10^{-6}\right)^{\mathrm{a}}$ \\
\hline
\end{tabular}

Note: ${ }^{\mathrm{a}} \mathrm{D}$ is actual distance measured by BeiDou, unit, $\mathrm{km}$.

In each test, the majority of prewetting water was uniformly sprayed onto the designated test plots by $U A V_{X}$. This water contained $232 \mathrm{ppm}$ dissolved solids. Taking into account the daily irrigation water applied during the flowering period of cotton in Xinjiang ${ }^{[20]}$, the maximum prewetting volume did not exceed the daily irrigation water quantity. The prewetting water volume for the four plots was $0,1.6,3.2$ and $4.8 \mathrm{~L}$ per $120 \mathrm{~m}^{2}$ (plots A-D, respectively). After prewetting, spraying with $U_{A V}$ was performed on plots in a single-pass according to set trajectory with flight height of $2 \mathrm{~m}$ and velocity of $4 \mathrm{~m} \cdot \mathrm{s}^{-1}$.

A Kestrel 5500 Link micro meteorological station (Nielsen-Kellerman Co., Boothwyn, PA, USA) was located at a height of $2 \mathrm{~m}$ above ground and well away from the flight route. The ambient weather data, including temperature, humidity, wind velocity and wind direction, was recorded every $5 \mathrm{~s}$ during the experiment.

After spraying, three samples were taken at each sampling point in the cotton canopy: sampling points 1$3\left(0^{\circ}-30^{\circ}\right.$ leaf blade angle $), 4-6\left(30^{\circ}-60^{\circ}\right)$, and $7-9\left(60^{\circ}-\right.$ $\left.90^{\circ}\right)$. Nine WSP sampling points were also placed at the corresponding angles in plot A to serve as controls for WSP analysis.

\subsection{Sampling methods}

\subsubsection{Water-sensitive paper collection and data processing}

After spraying of plot A by $\mathrm{UAV}_{\mathrm{Y}}$, the WSP cards were gathered immediately by an operator wearing disposable gloves, placed in marked envelopes and stored in a cool place until being transferred to the laboratory, where they were analyzed using image processing software, DepositScan (USDA. Wooster, OH, USA) and the droplet deposition quantity per card determined. The mean deposition quantity and coefficient of variation (CV) were also calculated and the $\mathrm{CV}$ was used to characterize the uniformity of the deposition distribution, the smaller the $\mathrm{CV}$, the more uniform of droplet deposition distribution.

\subsubsection{Cotton leaf collection and data processing}

When droplets on the cotton leaves had dried after each spraying application by $\mathrm{UAV}_{\mathrm{Y}}$, leaves were collected as described above for WSP. The absorbance values of different concentrations of ponceau $2 \mathrm{R}$ were first calibrated with detection wavelength of $504 \mathrm{~nm}$ by UV755B UV-Vis spectrophotometer (Youke Instrument Co., Ltd, Shanghai, China), and a standard curve of concentration and absorbance was obtained to facilitate the determination of the deposition quantity in the subsequent experiments (Fig. 3).
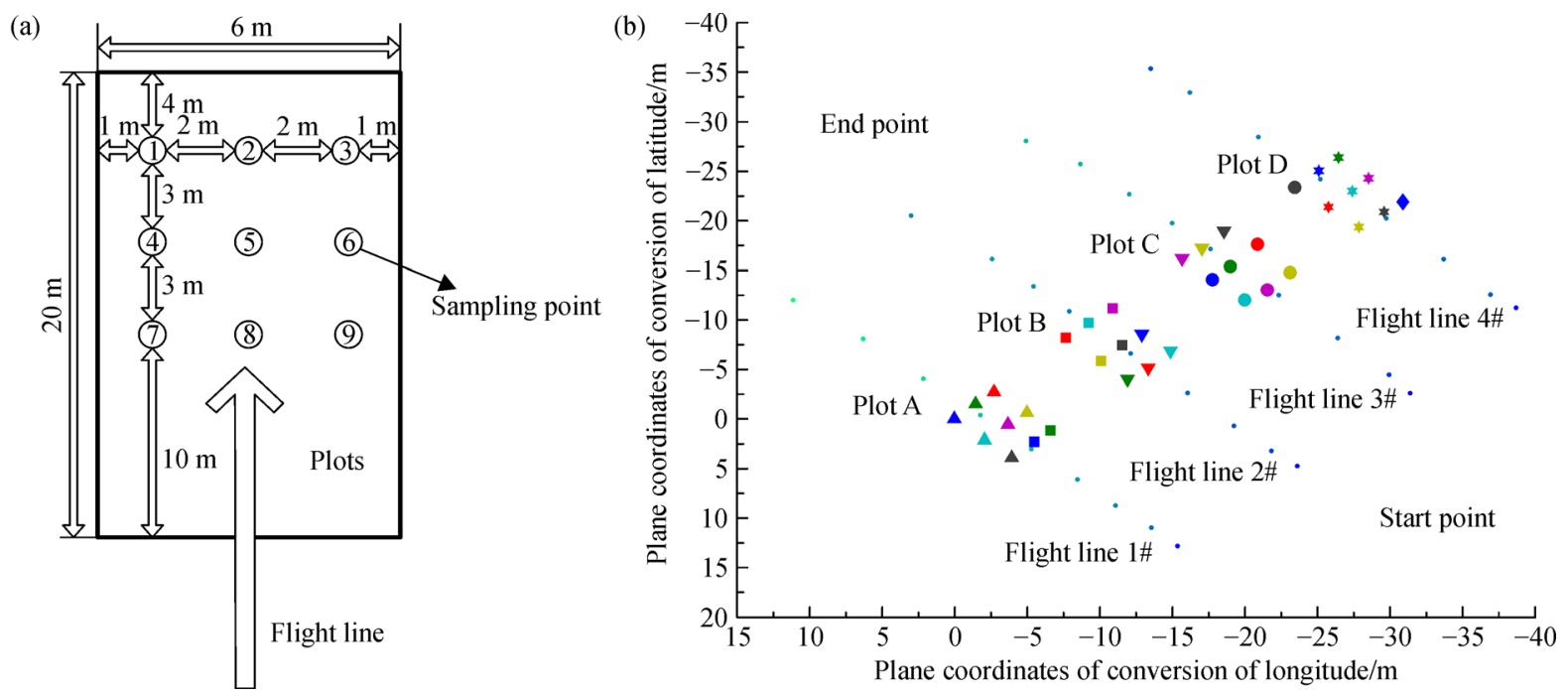

Fig. 2 Sampling points and flight trajectory. (a) Layout of sampling points; (b) measured flight trajectory. 


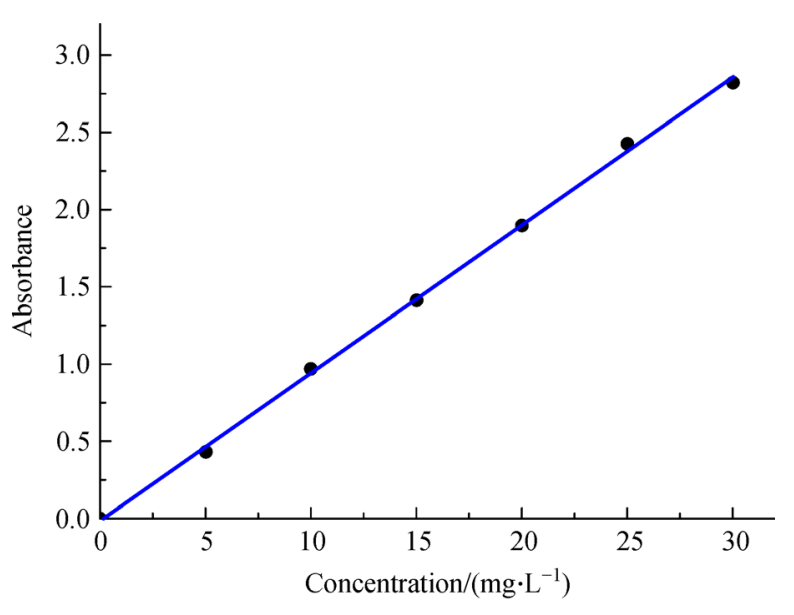

Fig. 3 Ponceau 2R standard curve

The standard curve equation was:

$$
y=0.0951 x-0.0129\left(R^{2}=0.9992\right)
$$

where $x$ is the concentration of ponceau $2 \mathrm{R}\left(\mathrm{mg} \cdot \mathrm{L}^{-1}\right)$, and $y$ is the absorbance values.

For each leaf analysis test, $20 \mathrm{~mL}$ of deionized water was added to the collection dish and eluted after 2-min agitation. Then the absorbance was measured by UV755B UV-Vis spectrophotometer at an absorption wavelength of $505 \mathrm{~nm}$. After absorbance measurements were completed, the cotton leaves were dried and individually scanned. The scanned images were processed by image processing software, Adobe PhotoShop CS6 (Adobe Systems Incorporated, San Jose, CA, USA), to determine the leaf area. The calculation formula for deposition was:

$$
\begin{gathered}
M_{\mathrm{d}}=\frac{x \times V_{\mathrm{w}}}{N \times A_{\mathrm{s}}} \\
M_{\mathrm{d}} \%=\frac{M_{\mathrm{d}} \times 10000}{M_{\mathrm{v}}}
\end{gathered}
$$

where $x$ is the concentration of ponceau $2 \mathrm{R}\left(\mathrm{mg} \cdot \mathrm{L}^{-1}\right) ; V_{\mathrm{w}}$ is the volume of eluent added $(\mathrm{mL}) ; N$ is the concentration of the spray liquid $\left(\mathrm{g} \cdot \mathrm{L}^{-1}\right) ; A_{\mathrm{s}}$ is the area of cotton leaves $\left(\mathrm{cm}^{2}\right) ; M_{\mathrm{d}}$ is the quantity of liquid deposited on cotton leaves $\left(\mu \mathrm{L} \cdot \mathrm{cm}^{-2}\right) ; M_{\mathrm{v}}$ is the setting spray volume, expressed in liters per hectare $\left(\mathrm{L} \cdot \mathrm{hm}^{-2}\right) ; M_{\mathrm{d}} \%$ is the measured deposition quantity as a percentage of the setting spray volume $(\%)$.

\subsubsection{Statistical analyses}

To further demonstrate the effect of prewetting on the deposition on cotton canopies with different leaf inclination angles, the prewetting volume was divided into four levels, and the deposition quantities on leaves of different inclinations analyzed by least-significant difference test $(P=0.05)$.

\section{Results and discussion}

\subsection{Operating parameters and environmental conditions}

After accurate measurements by the light airborne BeiDou RTK differential system, the flight height (distance from the cotton canopy), flight velocity and effective flight distance were obtained. For the four tests, the mean flight altitude was $1.86 \mathrm{~m}$ with $\mathrm{CV}$ of $4.46 \%$, and the mean flight velocity was $4.16 \mathrm{~m} \cdot \mathrm{s}^{-1}$ with $\mathrm{CV}$ of $4.09 \%$. $\mathrm{UAV}_{\mathrm{Y}}$ operational parameters and the corresponding meteorological data are showed in Table 2. It was confirmed that the actual operating parameters met the requirements of the test design.

\subsection{WSP analysis of droplet deposition}

The WSP analysis of droplet deposition for plot A is shown in Fig. 4. The horizontal coordinates indicate the position and leaf blade angle for each sampling point, and the vertical coordinates indicate the mean droplet deposition quantity corresponding to each sampling point.

The droplet deposition quantity at sampling points 2,5 and 8 down the center of the route was larger than for the sampling points to the sides of the route (Fig. 4). The mean droplet deposition in plot A was $0.056 \mu \mathrm{L} \cdot \mathrm{cm}^{-2}$ with $\mathrm{CV}$ of $36.0 \%$. The mean droplet deposition at sampling points $1-$ 3 for leaf blade angle of $0^{\circ}-30^{\circ}$ was $0.065 \mu \mathrm{L} \cdot \mathrm{cm}^{-2}$, for points $4-6$ at $30^{\circ}-60^{\circ}$ it was $0.058 \mu \mathrm{L} \cdot \mathrm{cm}^{-2}$, and for points $7-9$ at $60^{\circ}-90^{\circ}$ it was $0.047 \mu \mathrm{L} \cdot \mathrm{cm}^{-2}$. The highest value occurred at $0^{\circ}-30^{\circ}$ at points $1-3$ and the lowest at $60^{\circ}-$ $90^{\circ}$ in points $7-9$. WSP analysis showed that the droplet

Table 2 Relevant test parameters

\begin{tabular}{lcccccc}
\hline Test plots & $\begin{array}{c}\text { Wind velocity and direction } \\
/\left(\mathrm{m} \cdot \mathrm{s}^{-1}\right)\end{array}$ & $\begin{array}{c}\text { Mean } \\
\text { temperature } /{ }^{\circ} \mathrm{C}\end{array}$ & $\begin{array}{c}\text { Mean } \\
\text { humidity } / \%\end{array}$ & $\begin{array}{c}\text { Flight } \\
\text { height } / \mathrm{m}\end{array}$ & $\begin{array}{c}\text { Flight } \\
\text { velocity } /\left(\mathrm{m} \cdot \mathrm{s}^{-1}\right)\end{array}$ & $\begin{array}{c}\text { Effective flight } \\
\text { distance } / \mathrm{m}\end{array}$ \\
\hline A & $1.1 \mathrm{SE}$ & 31.2 & 30.2 & 1.93 & 4.03 & 36.33 \\
$\mathrm{~B}$ & $0.7 \mathrm{SE}$ & 30.7 & 31.6 & 1.89 & 4.09 & 36.84 \\
$\mathrm{C}$ & $0.8 \mathrm{SE}$ & 30.1 & 33.7 & 1.88 & 4.11 & 37.01 \\
$\mathrm{D}$ & $0.9 \mathrm{SE}$ & 29.4 & 31.1 & 1.74 & 4.41 & 35.31 \\
\hline
\end{tabular}




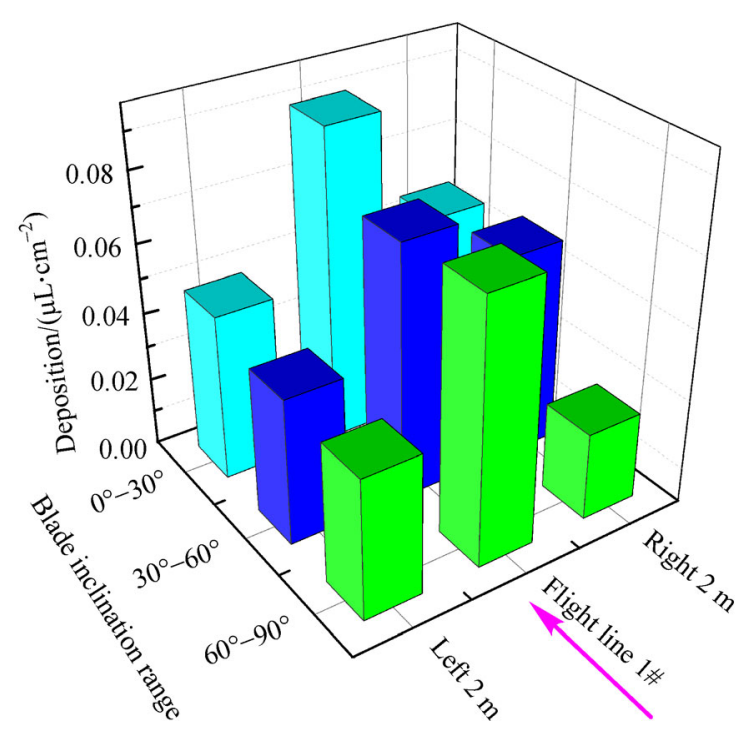

Fig. 4 Droplets deposition in plot A at three leaf blade angles

deposition decreased gradually with the increase of blade inclination.

\subsection{Elution analysis of droplet deposition}

The percentage mean droplet deposition of the set spray volumes for each prewetting spray test are shown in Fig. 5. The mean droplet deposition quantities in plots A-D were $30.8 \%, 43.1 \%, 33.8 \%$ and $38.5 \%$ of the total spraying quantity, respectively. Compared with plot A without a water prewetting treatment, the droplet deposition in plots B-D increased by $39.8 \%, 9.7 \%$ and $24.9 \%$, respectively, after different degrees of prewetting treatment.

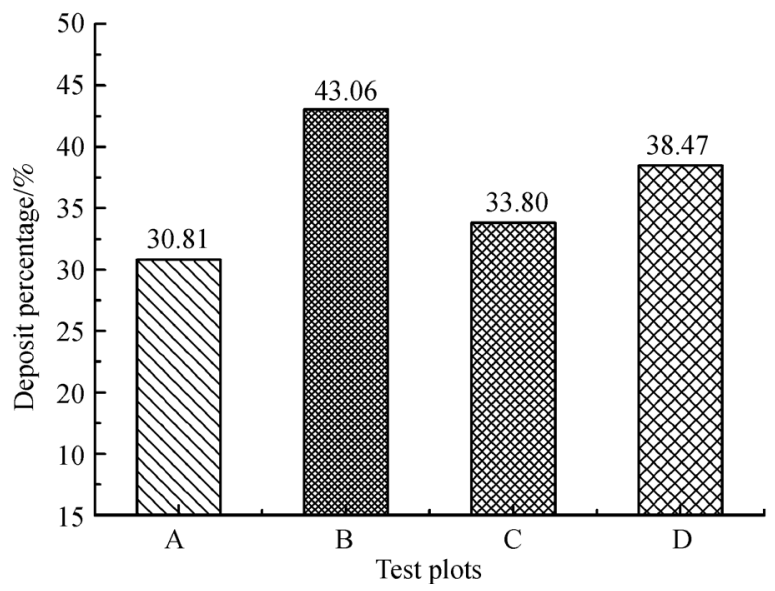

Fig. 5 Percentage of mean droplet deposition in each of the four test plots

The percentage of droplet deposition of the set spray volume at each sampling point for each prewetting spray test is shown in Fig. 6. Sampling point 2 in plots B and D

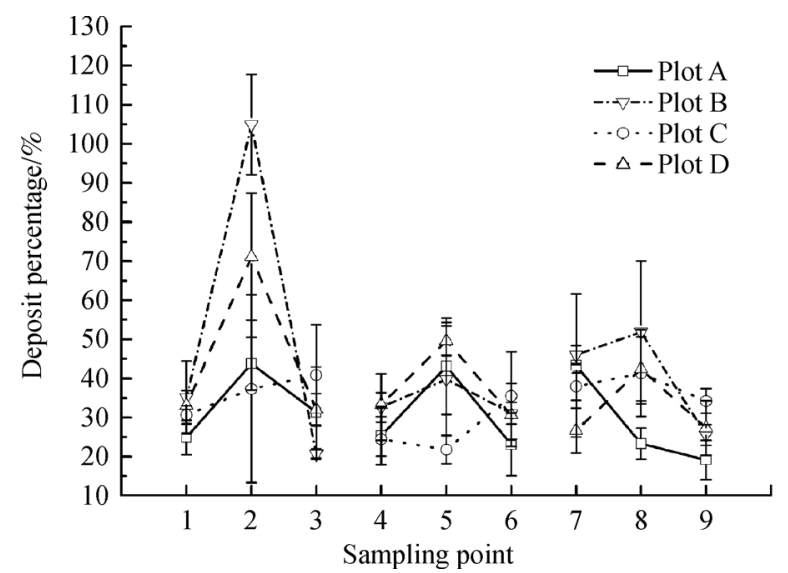

Fig. 6 Variation percentage of deposition quantity in each plot at 9 sampling points

had the largest increase in droplet deposition, $140 \%$ and $62 \%$, respectively. Also, the difference between droplet deposition under the center of the route and the sides of the route decreased gradually with the increasing inclination of the leaf blades.

To further examine the difference in droplet deposition with different water prewetting volumes and leaf blade inclinations, the mean droplet deposition for each angle range was calculated. The results (Table 3 ) shows that when prewetting was not performed, the droplet deposition quantity decreased with the increasing leaf blade inclination. After prewetting, the mean droplet deposition in each angle range increased, with the increase for leaf blade angle range of $60^{\circ}-90^{\circ}$ the greatest, increasing from 0.043 to 0.062 and $0.057 \mu \mathrm{L} \cdot \mathrm{cm}^{-2}$ in plots B and $\mathrm{C}$, respectively.

In addition, with the increase in prewetting volume, the mean droplet deposition quantity for each leaf blade angle showed an increasing then decreasing trend. The reason for this phenomenon is that the presence of prewetting water can reduce the droplet bounce, and lead to an increase in droplet deposition. However, if the volume of prewetting water is too great, close to or exceeding the maximum retention of cotton leaves, this can result in the subsequent spray application reaching the depositional loss point, thereby reducing the quantity of spray deposited.

According to the statistical analysis (Table 3 ), for leaf blade angles $0^{\circ}-30^{\circ}$ and $60^{\circ}-90^{\circ}$ there were significant differences between no prewetting and prewetting at $1.6 \mathrm{~L}$ per $120 \mathrm{~m}^{2}$, whereas for $30^{\circ}-60^{\circ}$ there was not significant effect. Also, for $60^{\circ}-90^{\circ}$ with prewetting of $3.2 \mathrm{~L}$ per $120 \mathrm{~m}^{2}$ the deposition was significantly greater than with no prewetting.

The results (Table 4) show that the deposition uniformity deteriorated with prewetting at the leaf blade angle range of $0^{\circ}-30^{\circ}$. It was concluded that this was related to the large increase in deposition quantity at some sampling points after prewetting. Deposition uniformity for $30^{\circ}-60^{\circ}$ and $60^{\circ}-90^{\circ}$ after prewetting improved significantly, 
Table 3 Droplet deposition at different prewetting volumes and leaf blade inclinations

\begin{tabular}{|c|c|c|c|c|}
\hline \multirow{2}{*}{ Plots } & \multirow{2}{*}{ Prewetting volume/(L per $\left.120 \mathrm{~m}^{2}\right)$} & \multicolumn{3}{|c|}{ Mean droplets deposition at each angle range $/\left(\mu \mathrm{L} \cdot \mathrm{cm}^{-2}\right)$} \\
\hline & & $0^{\circ}-30^{\circ}$ & $30^{\circ}-60^{\circ}$ & $60^{\circ}-90^{\circ}$ \\
\hline $\mathrm{A}$ & 0 & $0.050 \mathrm{a}$ & $0.046 \mathrm{a}$ & $0.043 \mathrm{a}$ \\
\hline $\mathrm{B}$ & 1.6 & $0.080 \mathrm{~b}$ & $0.052 \mathrm{a}$ & $0.062 \mathrm{~b}$ \\
\hline $\mathrm{C}$ & 3.2 & $0.054 \mathrm{a}$ & $0.041 \mathrm{a}$ & $0.057 \mathrm{~b}$ \\
\hline $\mathrm{D}$ & 4.8 & $0.068 \mathrm{ab}$ & $0.057 \mathrm{a}$ & $0.048 \mathrm{ab}$ \\
\hline Mean value & & 0.063 & 0.049 & 0.052 \\
\hline
\end{tabular}

Note: Means followed by the same letter within a column are not significantly different $(\mathrm{LSD}, P<0.05)$

Table 4 Droplet deposition uniformity at different prewetting volumes and blade inclinations

\begin{tabular}{lcccc}
\hline \multirow{2}{*}{ Test plot } & Prewetting volume/(L per $\left.120 \mathrm{~m}^{2}\right)$ & \multicolumn{3}{c}{ Droplets deposition uniformity at each angle range/\% } \\
\cline { 3 - 5 } & 0 & $0^{\circ}-30^{\circ}$ & $30^{\circ}-60^{\circ}$ & $60^{\circ}-90^{\circ}$ \\
A & 1.6 & 32.8 & 41.0 & 51.9 \\
B & 3.2 & 74.3 & 27.3 & 36.8 \\
C & 4.8 & 39.6 & 32.7 & 17.8 \\
D & & 46.5 & 26.5 & 30.6 \\
Mean value & & 48.3 & 31.9 & 34.2 \\
\hline
\end{tabular}

perhaps because at these larger leaf blade angles the droplets were more likely to spread by gravity improving the effectiveness of prewetting. In addition, it was likely to be more effective in reducing bounce and slippage of droplets on prewet leaves compared with the dry leaves at the same angle, so both droplet deposition quantity and uniformity improved.

\subsection{Comparison of WSP and elution analysis of droplet deposition}

Taking plot A spraying as an example, the results showed that the trends in droplet deposition were consistent between the two analytical methods. The elution analysis of droplets deposition per unit area of cotton leaf on plot A showed that the mean droplet deposition quantity at sampling points $1-3$ for $0^{\circ}-30^{\circ}$ blade inclination was $0.050 \mu \mathrm{L} \cdot \mathrm{cm}^{-2}$, at points $4-6$ for to $30^{\circ}-60^{\circ}$ it was $0.046 \mu \mathrm{L} \cdot \mathrm{cm}^{-2}$, and at points $7-9$ for $60^{\circ}-90^{\circ}$ it was $0.043 \mu \mathrm{L} \cdot \mathrm{cm}^{-2}$. Also, droplet deposition quantity decreased gradually with increasing blade inclination, which was similar to the results of WSP analysis. However, the mean droplet deposition quantity of plot A measured using WSP was $0.056 \mu \mathrm{L} \cdot \mathrm{cm}^{-2}$, whereas measured by leaf elution it was $0.046 \mu \mathrm{L} \cdot \mathrm{cm}^{-2}$. Likewise, the values at each angle range were also larger using WSP compared to leaf elution.

The difference in measurement method might be the main cause of this phenomenon, the material and shape of WSP were different from cotton leaves, and WSP had a strong hydrophilicity with color changing immediately after contact with water. When the droplets fall on the cotton leaves they can bounce or slip leaving no or minimal deposition, while droplets that contacted the WSP, due to the characteristics of WSP, do not bounce and slip, but immediately cause color changes recorded as deposition. Therefore, under the same spraying conditions, WSP and elution analysis results will be different.

\section{Conclusions}

In this research, flowering cotton plants were sprayed with $0.8 \%(\mathrm{w} / \mathrm{v})$ ponceau $2 \mathrm{R}$ by an electric single-rotor UAV after prewetting at different volumes. By comparing the relationship between prewetting volume, inclination of the leaves and droplet deposition quantity and uniformity, the following conclusions were drawn.

(1) Prewetting significantly increased the quantity of liquid droplets on the cotton leaves.

(2) Different prewetting volume had different effects on droplet deposition. The most significant increase compared to no prewetting was observed with prewetting of $1.6 \mathrm{~L}$ per $120 \mathrm{~m}^{2}$.

(3) Different leaf inclinations had different effects on droplet deposition. Without prewetting, the droplet deposition quantity decreased with increasing leaf blade angle. After prewetting, the mean droplet deposition quantity increased across all leaf blade angles, and this was most obvious for leaf blades at $60^{\circ}-90^{\circ}$. Also, with the increasing of prewetting volume, the mean droplet deposition quantity first increased then decreased.

(4) Droplet deposition without prewetting using WSP and ponceau $2 \mathrm{R}$ elution methods showed consistent trends, 
although the estimates of droplet deposition quantities were slightly higher using theWSP method.

Acknowledgements We are sincerely thankful for the financial support given by the National Key Technologies Research and Development Program (2016YFD0200700). We also thank the National Center for International Collaboration Research on Precision Agricultural Aviation Pesticides Spraying Technology and Shihezi University for the dedicated participation their staff in the experiment (Sheng Wen, Jiyu Li, Xia Zhang, Wei Fu, Tianzhu Duan, Xingzuo Sun, Hong Cheng, and Junsheng Ren). The High Technology New Farming Co., Ltd is thanked for its strong support.

Compliance with ethics guidelines Weixiang Yao, Xianju Wang, Yubin Lan, and Ji Jin declare that they have no conflicts of interest or financial conflicts to disclose.

This article does not contain any studies with human or animal subjects performed by any of the authors.

\section{References}

1. Wood W, Gore J, Catchot A, Cook D, Dodds D, Krutz L J. Susceptibility of flowering cotton to damage and yield loss from tarnished plant bug (Hemiptera: Miridae). Journal of Economic Entomology, 2016, 109(3): 1188-1195

2. Han H L, Kang F J. Experiment and study on effect of moisture coerce on cotton producing. Transactions of the Chinese Society of Agricultural Engineering, 2001, 17(3): 37-40 (in Chinese)

3. Echer F R, Rosolem C A. Cotton yield and fiber quality affected by row spacing and shading at different growth stages. European Journal of Agronomy, 2015, 65: 18-26

4. Willrich M M, Leonard B R, Temple J. Injury to preflowering and flowering cotton by brown stink bug and southern green stink bug. Journal of Economic Entomology, 2004, 97(3): 924-933

5. Giles D K, Billing R. Unmanned aerial platforms for spraying: deployment and performance. Aspects of Applied Biology, 2014, (122): 63-69

6. Zhang P, Deng L, Lyu Q, He S L, Yi S L, Liu Y D, Yu Y X, Pan H Y. Effects of citrus tree-shape and spraying height of small unmanned aerial vehicle on droplet distribution. International Journal of Agricultural and Biological Engineering, 2016, 9(4): 45-52

7. Ma X Y, Wang Z G, Jiang W L, Ren X L, Hu H Y, Ma Y J, Ma Y. Analysis of current status and application prospects of unmanned aerial vehicle plant protection technology in cotton field in China. China Cotton, 2016, 43(6): 7-11
8. Lan Y B, Chen S D, Fritz B K. Current status and future trends of precision agricultural aviation technologies. International Journal of Agricultural and Biological Engineering, 2017, 10(3): 1-17

9. Huang Y B, Hoffman W C, Lan Y B, Fritz B Z, Thomson S J. Development of a low-volume sprayer for an unmanned helicopter. Journal of Agricultural Science, 2015, 7(1): 148-153

10. Fritz B K, Hoffmann W C, Bagley W E, Hewitt A, Devisetty B, Dean S W. Field scale evaluation of spray drift reduction technologies from ground and aerial application systems. Journal of ASTM International, 2011, 8(5): 1-11

11. Zhang H J, Dong H Z, Li W J, Zhang D M. Effects of soil salinity and plant density on yield and leaf senescence of field-grown cotton. Journal Agronomy \& Crop Science, 2012, 198(1): 27-37

12. Yang X W, Dai M L, Song J L, Zhao J K, He X K. Effect of droplet size, leaf characteristics and angle on pesticide deposition. Transactions of the Chinese Society of Agricultural Engineering, 2012, 28(3): 70-73 (in Chinese)

13. Xu D J, Xu G C, Xu X L, Gu Z Y. Effect of application volume, droplet size, rice leaf incline angle and spray adjuvant on pesticide deposition. Southwest China Journal of Agricultural Sciences, 2015, 28(5): 2056-2062 (in Chinese)

14. Lan Y B, Hoffmann W C, Fritz B K, Martin D E, Lopez J D Jr. Spray drift mitigation with spray mix adjuvants. Applied Engineering in Agriculture, 2008, 24(1): 5-10

15. Jia W, Zhu H. Dynamics of water droplet impact and spread on soybean leaves. Transactions of the ASABE, 2015, 58(4): 10091016

16. Wang B, Song J L, Zeng A J, Liu Y J, Zhang J, He X K. Influence of dew on pesticide droplet deposition on rice leaves. Journal of China Agricultural University, 2012, 17(3): 94-100 (in Chinese)

17. Biance A L, Clanet C, Quéré D. First steps in the spreading of a liquid droplet. Physical Review E: Statistical, Nonlinear, and Soft Matter Physics, 2004, 69(1): 016301

18. Liu Y, Choi C H. Condensation-induced wetting state and contact angle hysteresis on superhydrophobic lotus leaves. Colloid \& Polymer Science, 2013, 291(2): 437-445

19. Yarin A L. Drop impact dynamics: splashing, spreading, receding, bouncing. Annual Review of Fluid Mechanics, 2005, 38(1): 159192

20. Cheng Q, Huang C Y, Wang D W, Xiao L J. Correlation between CWSI from infrared thermography and photosynthetic parameters during flowering and boll- forming stage of cotton. Xinjiang Agricultural Sciences, 2012, 49(6): 999-1006 (in Chinese) 